\title{
MPC MAJOR RESEARCH PROJECT
}

Access denied: Exploring web accessibility standards and their implications for users with cognitive impairments

\section{MATTHEW MENDONCA}

\section{Robert Clapperton}

The Major Research Paper is submitted in partial fulfillment of the requirements for the degree of Master of Professional Communication.

\author{
Ryerson University
}

Toronto, Ontario, Canada

August 27, 2015 


\section{Author's Declaration for Electronic Submission of a Major Research Paper}

I hereby declare that I am the sole author of this Major Research Paper and the accompanying Research Poster. This is a true copy of the MRP and the research poster, including any required final revisions, as accepted by my examiners.

I authorize Ryerson University to lend this major research paper and/or poster to other institutions or individuals for the purpose of scholarly research.

I further authorize Ryerson University to reproduce this MRP and/or poster by photocopying or by other means, in total or in part, at the request of other institutions or individuals for the purpose of scholarly research.

I understand that my MRP and/or my MRP research poster may be made electronically available to the public. 


\begin{abstract}
This Major Research Paper (MRP) explores the language and conceptual organization of the WCAG 2.0 Guidelines, a universal web accessibility document that aims to guide the development of accessible websites for users with sensory, motor and cognitive disabilities. This MRP attempts to bridge the gap between the study of user behaviours of individuals with cognitive impairments and the language and prioritization schema WCAG 2.0 uses to address accessibility. A structured literature review of contemporary usability studies involving users with cognitive impairments identifies webrelevant behaviours unique to these users and provides a rudimentary introduction to the online barriers they face. A qualitative content analysis reveals, in depth, how the language and conceptual organization of WCAG 2.0 frame cognitive impairments as less important than sensory impairments. Barriers for users with cognitive impairments are less frequently addressed, and when they are, they are often given a level AAA priority designation, the least essential priority according to the WCAG 2.0 Guidelines. Individual criteria are further analyzed in the Discussion, where the themes and results of the content analysis culminate in recommendations for web developers.
\end{abstract}




\section{Table of Contents}

1.1 WCAG 2.0 Guidelines

1.2 Cognitive impairments and the problem at hand 3

$\begin{array}{ll}2.0 \text { Literature review } & 4\end{array}$

2.1 Recognizing the web as a multimodal environment 4

2.2 Understanding the importance of the user experience $\quad 6$

2.3 Designing an inclusive web 9

$\begin{array}{ll}\text { 3.0 Methods } & 12\end{array}$

3.1 Structured literature review of usability studies 12

3.2 Content analysis of the WCAG 2.0 document 14

4.0 User experiences of individuals with cognitive impairments 16

$\begin{array}{ll}4.1 \text { Affected user groups } & 17\end{array}$

$\begin{array}{ll}\text { 4.2 Memory impairments } & 18\end{array}$

4.3 Attention impairments 20

4.4 Language impairments $\quad 22$

5.0 Content analysis of WCAG 2.0 23

5.1 Web content addressed by WCAG 2.0

5.2 Language in WCAG 2.0 26

5.3 Detailed analysis of success criteria $\quad 29$

6.0 Discussion: Identifiable issues with WCAG 2.0, web accessibility and 35 $\begin{array}{ll}\text { cognitive impairments } & 35\end{array}$

6.1 Defining what is accessible $\quad 35$

6.2 The problem with level AAA priority 37

$\begin{array}{ll}7.0 \text { Conclusion } & 39\end{array}$

$\begin{array}{ll}7.1 \text { Recommendations } & 40\end{array}$

$\begin{array}{ll}\text { 7.2 Moving forward } & 42\end{array}$

$\begin{array}{ll}\text { References } & 43\end{array}$ 


\section{List of Tables}

Table 1: Coding Scheme for Language Assessment of Whole Guidelines 15

Table 2: Coding Scheme for Intent of Success Criterion Sections 16

Table 3: User Groups and Impacted Cognitive Function Overview 17

Table 4: Impaired Memory Function and Corresponding User Behaviours 19

Table 5: Impaired Attention Function and Corresponding User Behaviours 21

Table 6: Impaired Language Function and Corresponding User Behaviours 22

Table 7: Web Content Barriers Addressed in WCAG 2.0 Main Content 24

Table 8: Occurrences of Most Frequent Words in WCAG 2.0 Guidelines 26

Table 9: Occurrences of Key Words in "Intent" Sections 28 


\section{ACCESS DENIED}

Access denied: Exploring web accessibility standards and their implications for users with cognitive impairments

Many websites in the current web 2.0 landscape exclude certain users by presuming they have the physical and mental capability to access and navigate the web without obstruction. For many users, sensory, motor and cognitive impairments hinder everyday web communication. For example, a user with a visual impairment may have difficulty reading small text on a page. A motor impairment may restrict a user's ability to navigate with a mouse. A cognitive impairment, such as impaired memory, may cause a user to lose track of where he or she is on a page. Most web users take for granted their ability to carry out online tasks with little inherent disruption, but for millions of users, physical and mental impairments limit operability on the web. When a website restricts a user's ability to effectively navigate and communicate online, the website is considered inaccessible.

An accessible website provides equal opportunity for all users, regardless of ability or disability, to operate and communicate online without interference (Neilsen, 2000, p. 12). Accessible websites have adaptable or modified content, which includes text, images, video, sound, page layout and organization, that can be understood by most or all user groups (W3C, 2008).

\subsection{WCAG 2.0 Guidelines}

In an attempt to create a universal standard for web accessibility, the World Wide Web Consortium (W3C), an international community of organizations led by Tim BernersLee, created the Web Content Accessibility Guidelines (WCAG) in 1999. WCAG 1.0 was 


\section{ACCESS DENIED}

the first attempt to provide web content developers with measurable criteria to guide the evaluation of web accessibility. The criteria have since been adapted to reflect the increasing complexity of web development technology and the growing understanding of user experience. In 2008, WCAG 2.0 was released and remains the current standard of web accessibility as set forth by the $\mathrm{W} 3 \mathrm{C}$. The guidelines are divided into four general principles and further subdivided into 12 guidelines and 61 success criteria. Each success criterion is either machine testable or reliably human testable. Machine testability refers to an algorithm's or automated program's ability to determine if a criterion is met. Human testability refers to the ability of web accessibility experts to agree on the success of a criterion $80 \%$ of the time (W3C, 2008).

The success criteria are also categorized in priority levels: level A, level AA and level AAA. According to the WCAG 2.0 document, level A criteria are prioritized as the most essential to accessibility (W3C, 2008). They are also the least likely to impede the "look and feel" of a web page and can be "reasonably achieved by content creators by a skill that could be acquired in a week's training or less" (W3C, 2008). Level AAA criteria are prioritized as the least essential and usually require more accessibility training for content creators.

The WCAG 2.0 success criteria are benchmarks for web accessibility evaluation around the globe. Many popular automated evaluation tools adapt the machine testable criteria from WCAG 2.0 in their algorithms. These success criteria also provide the backbone for many accessibility compliance laws, such as the Accessibility for Ontarians with Disabilities Act (AODA). AODA requires, by law, all public websites, non-profit and 


\section{ACCESS DENIED}

private business sector websites achieve level A compliance with WCAG 2.0 success criteria (AODA, 2014). As a measure of evaluating web accessibility, the WCAG 2.0 success criteria have become the default standard around the globe (W3C, 2015).

\subsection{Cognitive impairments and the problem at hand}

The WCAG 2.0 Guidelines have many shortcomings. The success criteria only address barriers that can be reliably tested for inaccessibility and, since many important barriers to accessibility are not reliably testable or quantifiable, WCAG 2.0 Guidelines tend to overlook or incorrectly identify these barriers and their solutions. These barriers typically affect users with cognitive impairments. According to Web Accessibility In Mind (WebAIM), a W3C working group that helped draft WCAG 2.0, cognitive impairments are defined as "difficulty with one or more types of mental tasks" (2013), most often affecting memory, attention, verbal comprehension and visual comprehension. In 2012, almost 2 million Canadians reported having some degree of cognitive or learning disability and the prevalence of cognitive impairment only increases with age (Statistics Canada, 2012). Current research on cognitive impairments and web accessibility is significantly lacking compared to the existing research on sensory disabilities, such as vision or hearing loss (McCarthy \& Swierenga, 2009). WCAG 2.0 is commonly criticized for its vague and incomplete solutions for cognitive impairments, and with an aging, computer-literate population in Canada, this is a definite problem.

This Major Research Paper (MRP) explores how WCAG 2.0 success criteria address, through language, the barriers faced by users with cognitive impairments. Using 


\section{ACCESS DENIED}

current studies and resources on web usability and a detailed content analysis of the WCAG

2.0 Guidelines, this MRP seeks to answer the following research questions (RQs):

1. What behaviours do users with cognitive impairments demonstrate when navigating a website?

2. What barriers to accessibility do WCAG 2.0 success criteria attempt to flag and measure?

3. How do the language and the conceptual organization of the WCAG 2.0 success criteria address the barriers faced by users with cognitive impairments?

\subsection{Literature review}

The study of web accessibility and user experience is rooted in several theoretical fields. Literature on the theories of multimodality, user experience and inclusive design support the exploration into the effectiveness of WCAG 2.0.

\subsection{Recognizing the web as a multimodal environment}

The web is a multimodal platform. The evolution of the web 2.0 landscape and the subsequent increase in responsive digital communication has introduced an environment that utilizes multiple modes to communicate. Discursive and non-discursive modes of communication, including text, image, sound and spatial layout, help users create and decipher meaning. Each mode has unique affordances and, accordingly, certain groups of users interpret each mode differently. Images can provide rich detail to those with sight, but limit the transmission of information to those who are visually impaired. Complex language on a web page would exclude an audience with poor verbal comprehension skills.

Understanding how digital multimodality affects web communication provides preliminary 


\section{ACCESS DENIED}

insight into how users access (or fail to access) information. Knowing the benefits and limitations of modes of web communication is the foundation for determining the effectiveness of WCAG 2.0 as an evaluation standard.

Several publications and studies demonstrate the connection between the theory of multimodality and the access of information online. Kress and van Leeuwen were among the first to apply the theory of multimodality and multimodal affordance to web communication. In their first book, Kress and van Leeuwen (2001) emphasize the increasing importance of non-discursive modes of communication in the web environment. Non-discursive modes, such as image, video and spatial layout, offer unique value and meaning. Their affordances may benefit particular groups of users and exclude others from creating meaning. This is problematic, as Kress (2010) notes a production shift "from the dominance of the mode of writing to the modes of image, sound and video" (p. 36) in the mixed media web environment. While Kress and van Leeuwen do not allude to web accessibility specifically, their work contextualizes the problem with WCAG 2.0 and web accessibility evaluation. As meaning is created through different modes of communication, and WCAG 2.0 concerns technical and very specific testable areas of content development, certain modes of communication will be left vulnerable to inaccessibility by the WCAG 2.0 standards because testability measures for these modes do not exist.

Studies have demonstrated the impact of multimodality in web communication with quantifiable results. A study by Mahmud and Ramakrishnan (2012) compared the behaviours of sighted and non-sighted users when navigating online transactional websites. Conducting online transactions, such as online shopping or banking, is a popular online 


\section{ACCESS DENIED}

activity involving multiple steps. Mahmud and Ramakrishnan note the multistep process is layered and visual complex (2012, p. 384). When a user has to "locate relevant content" and "perform a sequence of steps" (Mahmud \& Ramakrishnan, 2012, p. 384), he or she is required to rely on visual cues and navigate through several pages. The multimodal nature of transactional websites resulted in "information overload" and made performance of transactional models "nearly impossible" for visually impaired users (Mahmud \& Ramakrishnan, 2012, p. 402). A similar survey of user behaviours conducted by Wei (2012) demonstrated the correlation between the number of modes a website used to communicate a message and the online user behaviours of targeted populations. Wei identified a "second-level digital divide" (2012, p. 304), where senior users had more trouble navigating and understanding websites that rely heavily on multimedia, such as YouTube and Facebook. Usability studies with senior populations are relevant to the study of accessibility because sensory, motor and cognitive decline comes with age. Both studies quantify the impact of multimodality in web communication. As the web grows increasingly multimodal and complex, users face more potential obstacles to web accessibility.

\subsection{Understanding the importance of the user experience}

Understanding the multimodal web 2.0 environment is the first step in exploring the effectiveness of WCAG 2.0 as an evaluative standard of web accessibility. The next step involves understanding how WCAG 2.0 success criteria benefit or limit the potential experience of web users by considering the study of user experience. When applied to the web, user experience theory explores individual user behaviours and attitudes involving 


\section{ACCESS DENIED}

website or web-based application interaction. It encompasses all aspects of an end-user's relationship with the web and is essential in the study of web accessibility. Certain navigational behaviours and communication techniques require accessible accommodations. Understanding the fundamental implications of user behaviour on web accessibility will help identify the strengths and shortcomings of WCAG 2.0 success criteria. To answer RQ 1, specific usability studies and literature with a focus on cognitive impairments will be explored in detail in section 4.0.

Several important studies anchor the exploration of user experience and its relationship to web accessibility. In their 2011 study, Caldwell and Vanderheiden explore user behaviours and appropriate accommodations for accessible navigation. They urge web developers and authors to consider the "full range of constraints that a user might be under and the fact that they need to not only be able to 'barely use' [the web feature] but be able to use it efficiently and effectively enough to carry out the intended function of the content" (Caldwell \& Vanderheiden, 2011, p. 385). These "constraints" are the basis of accessible accommodations on the web, bridging the theoretical gap between user experience and web accessibility. Understanding how a user experiences web content is essential to ensuring the web's operability. A similar conclusion is reached in the work of van Rijn, Johnson and Taatgen (2011), where the authors examine the increasing need to "personalize the Web for individual users or user groups" based on "observations of the user's [behaviour]" and empirical models of common web-based task performance (p. 530). In the section "Adaptive Elements," van Rijn et al. stress the need to adapt the presentation of content to accommodate various user behaviours by using the example of an interchangeable interface 


\section{ACCESS DENIED}

of text- and image-based content (van Rijn et al., 2011, p. 527). Some users struggle with verbal comprehension and, subsequently, process visual information more effectively. Such users would greatly benefit from an adaptable interface that allows efficient navigation across different modes. Adaptable interfaces are not always a feasible solution, but they are examples of how user experience influences the development of accessible content.

Literature on user experience theory often emphasizes the role of the web content developer. Encouraging web developers to consider unique user behaviours and integrate accessible solutions throughout content development reduces the risk of treating accessibility as a post-production afterthought. All web developers have individual biases that can make it difficult to understand how other users, particularly those with impairments, view and navigate online content. A study by Giakoumis et al. (2014) presented developers with a tool that allowed them to "experience accessibility limitations that can be posed from various disabilities during the interaction of impaired users with their developments" (p. 227). Using various techniques and filters, Giakoumis et al. simulated sensory and cognitive impairments to "allow designers to get an even more concrete insight of how symptoms of the covered impairments may hinder humancomputer interaction" (2014, p. 246). The method and purpose of this study hinges on the inherent connection between user experience and web accessibility. By understanding how particular users interact with websites, developers can create digital environments that accommodate the majority of users. Much like the theory of multimodality, user experience theory is a foundation upon which means of overcoming accessibility barriers for cognitive impairments can be assessed and corrected. 


\section{ACCESS DENIED}

\subsection{Designing an inclusive web}

The study of multimodality and user experience theory scaffold the exploration into inclusive design: the theory of multimodality illuminates the shortcomings of the web 2.0 environment, while user experience theory helps determine where accessible accommodations are necessary and, more importantly, where accessibility success criteria excel or fall short. From there, developers can create web content that is inclusive. Inclusive or universal design prioritizes the diversity of the World Wide Web's global user base (Clarkson et al., 2003, p. 14) Inclusive design is multifaceted; web accessibility is merely one component. The work of Cooper, Sloan, Kelly and Lewthwaite (2012) explain the interconnectivity of accessibility and inclusive design, noting web accessibility is determined by "complex political, social and other contextual factors," such as age and computer literacy (p. 1). Current evaluation methods and accessibility laws test technical artefacts against stagnant criteria; such a technical focus "inevitably divorces accessibility from user experience of disabled people" (Cooper et al., 2012, p. 2).

Several contemporary studies assess the viability of web accessibility standards, such as WCAG 2.0, at a much more detailed level, which helps answer RQ 2 and RQ 3. One such study by Brajnik, Yesilada and Harper (2012) looks at the human testability of the criteria in WCAG 2.0. As previously mentioned, WCAG 2.0 success criteria must be machine testable or reliably human testable. To be considered reliably human testable, $80 \%$ of human testers must agree on whether the criterion is met or not. In their study, Brajnik et al. found that $80 \%$ agreement was almost never found and "most success criteria would fall within the 'Not Reliably Testable' category in real world audits” (2012, p. 2). They 


\section{ACCESS DENIED}

independently tested the criteria with knowledgeable testers and a control group of novice testers. The authors conclude that reliable human testability is not attainable for WCAG 2.0 success criteria and, more importantly, measuring accessibility should be contextualized much like usability (Brajnik et al., 2012, p. 26). Brajnik et al. note that the fundamental principles guiding WCAG 2.0 are useful when viewed as “development guidelines”, not “test statements and criteria" as suggested by the W3C (2012, p. 27). Moreover, the imagined circumstances of the experiment may have resulted in a more shallow assessment by knowledgeable participants, having known the simulation was fictional. Nonetheless, the study points to the fundamental problem regarding the reliability and validity of WCAG 2.0 success criteria and their inability to accurately identify legitimate barriers to accessibility.

A similar study conducted by Vigo, Brown and Conway (2013) finds that developers who rely on evaluation tools using WCAG 2.0 success criteria as a baseline left websites inaccessible. Vigo et al. analyzed six major evaluation tools that use WCAG 2.0 as a baseline for measurement, finding that, at most, 50\% of WCAG 2.0 success criteria are correctly identified (2013, p. 8). Among the success criteria identified, they conclude that four out of ten are potentially a false positive identification (Vigo et al., 2013, p. 8). Like previous studies, Vigo and his team use expert evaluations and a rigid study design. The study focuses on static and dynamic pages, but not real-time multimedia, which is a potential limitation since video and live-streaming is increasing in popularity. The conclusion, however, is worth noting: if popular evaluation tools fail to flag $50 \%$ of WCAG 2.0 success criteria, the criteria may not be conclusively machine testable. This is a 


\section{ACCESS DENIED}

problem for developers who rely on automated testing of WCAG 2.0 criteria, as they may not be getting an accurate assessment of a website's accessibility.

WCAG 2.0 remains the current standard for web accessibility evaluation and the only published guidelines widely consulted and adopted (W3C, 2015). The success criteria remain static despite the increasing complexity and novelty of web technology. Recent studies demonstrate WCAG 2.0 has difficulty keeping up with contemporary web practices. A study by Romen and Svanaes (2011) tested usability and accessibility with a group of visually impaired users, as well as a control sighted group to "makes it possible to differentiate between usability problems and accessibility problems” (p. 378). In other words, if problems with a website were only experienced by the group of visually impaired users, then it points to an issue of accessibility, not usability. It was found that only $32 \%$ of accessibility problems could be identified by WCAG 2.0 criteria (Romen \& Svanaes, 2011, p. 382). The WCAG 2.0 Guidelines are unable to identify every potential problem, a trend that is bound to accelerate as web content development increases in complexity and the number of modalities grows.

This concern is a theme that recurs throughout the literature. Researchers Sloan and Kelly (2011) assert that there is a need to "address web accessibility measurement challenges within a wider real-world context" (p.1). Ignoring real-world scenarios and experience, and relying on algorithms that solely measure technical guidelines, can "lead to a danger that 'good enough' solutions may fail to consider a wider measure of user experience in accessible measurement" (Sloan \& Kelly, 2011, p. 1). There is a strong need for "more sophisticated models of understanding and addressing accessibility issues in a 


\section{ACCESS DENIED}

way that is sympathetic to current digital authoring" (Sloan \& Kelly, 2011, p. 2), particularly for organizations whose customers rely on inclusive online experiences.

Keeping the theoretical frameworks of multimodality, user experience and inclusive design in mind, this MRP seeks to understand how the language and conceptual organization in WCAG 2.0 addresses users with cognitive impairments and the barriers they face.

\subsection{Methods}

Investigating how the WCAG 2.0 success criteria address the barriers faced by users with cognitive impairments requires (1) an understanding of how such users interact with the web and, (2) a structured analysis of the guidelines themselves. This MRP unfolds in two stages. The first is a structured literature review of relevant usability and user experience studies and resources regarding individuals with cognitive impairments, with the goal of determining how the most common impairments to cognitive function affect using the web, answering RQ 1. The second stage involves a thorough content analysis of the WCAG 2.0 document, answering RQ 2 and 3.

\subsection{Structured literature review of usability studies}

In order to preface the content analysis of the WCAG 2.0 document, the ways in which users with cognitive impairments use the web must be better understood. No singular list of usability traits for individuals with cognitive impairments currently exists, so these traits must be gathered and extracted from contemporary usability studies and resources through a structured literature review. The study of usability is a growing field, but many contemporary studies prefer to use participants with visual and auditory impairments while 


\section{ACCESS DENIED}

participants with cognitive impairments remain underrepresented because sensory

disabilities are better understood by researchers and developers and have fewer performance variables, while cognitive impairments are complex and highly variable (Mariger, 2006).

Impairments to cognitive function are common to many disabilities, so, to remain within reasonable scope, data will be collected from 26 studies that focus on the most commonly impaired cognitive functions: memory, attention and verbal comprehension. Studies were gathered from the Scholars Portal Journals database; the database's wide range of disciplines suits the cross-disciplinary nature of usability and user experience studies. Inclusion criteria for the database search comprised of the three cognitive functions as well as commonly associated disorders, symptoms and user groups, including dyslexia, aphasia, dementia, Attention Deficit and Hyperactivity Disorder (ADHD) and Alzheimer's. Studies using participants with cognitive learning disabilities (CLDs) were included as most learning disabilities affect cognitive function (Learning Disabilities Association of Ontario, 2011). Studies with aging participants were also included if the authors discussed relevant associated impairments (e.g. memory loss, weakened attention span or poor verbal comprehension). There is high co-morbidity among those with functional cognitive impairments (American Psychiatric Association, 2015), meaning many of selected user groups have more than one cognitive impairment.

Publication dates earlier than 2005 were excluded from the search. The nature of human-computer interaction (HCI) is contingent on the web landscape and older studies may not accurately identify appropriate considerations for contemporary web users with 


\section{ACCESS DENIED}

cognitive impairments. As this field is still underdeveloped, relevant online resources were also consulted, including the W3C's Cognitive Accessibility User Research working draft, which aims to describe the "challenges of using web technologies for people with learning disabilities or cognitive disabilities" (2015, p. 1).

Collecting this data is an important step before analyzing the content of WCAG 2.0. Gathering a comprehensive list of user behaviours of those with cognitive impairments will help identify what WCAG 2.0 does well, where it needs improvement and what is missing altogether.

\subsection{Content analysis of the WCAG 2.0 document}

The content analysis of the WCAG 2.0 document aims to uncover what barriers to accessibility the success criteria attempt to measure (RQ 2) and identify what impairments are addressed in general. The WCAG 2.0 Guidelines were selected because they remain the most commonly referenced web accessibility guidelines internationally (WebAIM, 2013). Despite the guideline's age, it is still a frequent backbone to many relevant accessibility policies. To answer how the language and conceptual organization of WCAG 2.0 addresses the barriers and user experiences of individuals with cognitive impairments (RQ 3), the results of the content analysis are compared to the results of the structured literature review.

The content analysis was conducted manually and with automated software, using quantitative and qualitative techniques. First, all 61 success criteria were individually assessed to determine the usability barrier each criterion addresses. In WCAG 2.0, the descriptions of each criterion identifies the accessibility issue it attempts to overcome. Then, a more in-depth, language analysis was conducted with automated software, 


\section{ACCESS DENIED}

analyzing the entire text from the WCAG 2.0 Guidelines, including the more detailed "How to Meet" and "Understanding" sections. The top 500 words of the over 4,590 unique words in the document, omitting common stop words, were coded for language that made explicit reference to a particular accessibility barrier. Words were categorized as referencing sensory impairment, motor impairment, cognitive impairment or no distinct impairment/ other, as represented in Table 1 below. This particular analysis provides a shallow but illuminating overview of how often language in the WCAG 2.0 Guidelines addresses particular impairments.

Table 1 - Coding Scheme for Language Assessment of Whole Guidelines

\begin{tabular}{|l|l|l|l|l|} 
& $\mathbf{1}$-Sensory & $\mathbf{2}$ - Motor & $\mathbf{3}$ - Cognitive & $\mathbf{9}$ - Other \\
\hline Example: & $\begin{array}{l}\text { blind, vision, } \\
\text { hearing }\end{array}$ & $\begin{array}{l}\text { dexterity, tremor, } \\
\text { motor }\end{array}$ & $\begin{array}{l}\text { learning, } \\
\text { cognitive, } \\
\text { attention }\end{array}$ & $\begin{array}{l}\text { accessibility, feature, } \\
\text { text }\end{array}$ \\
\hline
\end{tabular}

The rest of the content analysis was conducted manually because an analysis dependent on context provides a more realized evaluation of language and its meaning. Each criterion's "Intent" section spells out which user groups benefit from the criterion and how they benefit. All 61 "Intent" sections were manually analyzed and coded through inductive analysis, using a similar coding scheme as that above. In addition to analyzing individual words, phrases and small sentences were also included. Only content that referenced a specific barrier or user group was considered. Some phrases applied to multiple impairments and were categorized separately to ensure mutual exclusivity in the coding scheme presented in Table 2 below. In addition, the criteria were analyzed by priority level to observe and report any trends based on importance and priority. 


\section{ACCESS DENIED}

Table 2 - Coding Scheme for Intent of Success Criterion sections

\begin{tabular}{|c|c|c|c|c|c|}
\hline & 1 - Sensory & 2 - Motor & 3 - Cognitive & $\begin{array}{l}4 \text { - Multiple } \\
\text { Impairments }\end{array}$ & 9 - Other \\
\hline Example: & $\begin{array}{l}\text { "people who } \\
\text { are deaf-blind" } \\
\text { "cannot hear } \\
\text { an audio file" }\end{array}$ & $\begin{array}{l}\text { "people with } \\
\text { hand tremors" } \\
\text { "dexterity } \\
\text { impairment" }\end{array}$ & $\begin{array}{l}\text { "those with } \\
\text { cognitive } \\
\text { limitations" } \\
\text { "learning } \\
\text { disabilities" }\end{array}$ & $\begin{array}{l}\text { "people with } \\
\text { difficulty } \\
\text { perceiving visual } \\
\text { content" } \\
\text { "people with } \\
\text { different } \\
\text { disabilities" }\end{array}$ & $\begin{array}{l}\text { "text can be } \\
\text { rendered in a } \\
\text { variety of ways" }\end{array}$ \\
\hline
\end{tabular}

\subsection{User experiences of individuals with cognitive impairments}

According to WebAIM, cognitive impairments are "the least understood and the least discussed type of disability among web developers" (2013). Studies of the needs and behaviours of individuals with cognitive impairments are often vague, speculative and variable, and, compared to users with sensory disorders, fewer accessibility and usability studies focus on them. As the W3C states, it is "no surprise that the cognitive disability sciences have not yet yielded a well-defined set of recommendations for web developers" (WebAIM).

However, a handful of usability and accessibility studies observe the behaviours of particular user groups whose memory, attention and verbal comprehension is impaired. A total of 26 published studies since the year 2005 were examined in detail, along with the W3C's working report on Cognitive Accessibility User Research. User behaviours were extracted from the results of the studies and papers, then compiled and organized for each cognitive function. As some studies tested user groups with comorbidity of impaired cognitive function, such as aging populations or those with cognitive learning disabilities, those studies presented results for more than one type of user behaviour (e.g. users with both memory and attention impairment). 


\section{ACCESS DENIED}

Before each cognitive function and its impact on web usability is discussed, the

following section highlights the characteristics of various user groups who participated or were subjects of observation in the 26 published studies.

\subsection{Affected user groups}

It is much easier for researchers to test subjects with documented and diagnosed disabilities than it is to study isolated cognitive functions, such as memory impairment. The following user groups were the focus of the studies in question. The information gathered in Table 3 below was derived from the studies in question and the DSM-5 (American Psychiatric Association, 2015).

Table 3 - User Groups and Impacted Cognitive Function Overview

\begin{tabular}{|c|c|c|c|c|}
\hline User Group & Definition & Memory & Attention & $\begin{array}{l}\text { Language } \\
\text { Comprehension }\end{array}$ \\
\hline Dyslexia & $\begin{array}{l}\text { A categorized learning } \\
\text { disability, dyslexia is a } \\
\text { general category of } \\
\text { disorder that affects } \\
\text { development of literacy } \\
\text { and language-related skills. } \\
\text { It is the consequence of } \\
\text { altered neural pathways in } \\
\text { regions of the brain } \\
\text { associated with the reading } \\
\text { process. }\end{array}$ & $\begin{array}{l}\text { Dyslexia affects: } \\
\text { - short-term } \\
\text { memory } \\
\text { - visuo-spatial } \\
\text { memory } \\
\text { - } \text { auditory } \\
\text { memory } \\
\text { - procedural } \\
\text { memory }\end{array}$ & $\begin{array}{l}\text { Dyslexia affects: } \\
\text { - selective } \\
\text { attention }\end{array}$ & $\begin{array}{l}\text { Dyslexia affects: } \\
\text { - literacy } \\
\text { - } \text { perception of } \\
\text { written language } \\
\text { - } \text { related memory } \\
\text { - } \text { temporal tracking }\end{array}$ \\
\hline Aphasia & $\begin{array}{l}\text { Aphasia causes } \\
\text { comprehension and } \\
\text { speech and language } \\
\text { difficulties, so affected } \\
\text { individuals have trouble } \\
\text { processing and producing } \\
\text { language. Often the result } \\
\text { of a stroke or traumatic } \\
\text { brain injury (TBI). }\end{array}$ & $\begin{array}{l}\text { Aphasia affects: } \\
\text { - short-term } \\
\text { memory } \\
\text { - visuo-spatial } \\
\text { memory } \\
\text { - procedural } \\
\text { memory }\end{array}$ & $\begin{array}{l}\text { Aphasia affects: } \\
\text { - attention span } \\
\text { (is shortened) }\end{array}$ & $\begin{array}{l}\text { Aphasia affects: } \\
\text { - } \text { difficulty coping } \\
\text { with sounds that } \\
\text { make up speech } \\
\text { - understanding } \\
\text { figural language } \\
\text { - literacy } \\
\text { - } \text { recognition of } \\
\text { letters and words }\end{array}$ \\
\hline
\end{tabular}


ACCESS DENIED

\begin{tabular}{|c|c|c|c|c|}
\hline User Group & Definition & Memory & Attention & $\begin{array}{l}\text { Language } \\
\text { Comprehension }\end{array}$ \\
\hline $\begin{array}{l}\text { Language } \\
\text { impairments }\end{array}$ & $\begin{array}{l}\text { Language impairments } \\
\text { refer to the broad category } \\
\text { of non-verbal and speech } \\
\text { impaired users who, like } \\
\text { those with aphasia, may } \\
\text { have difficulty with } \\
\text { comprehension and } \\
\text { production of language. In } \\
\text { this case, the language } \\
\text { impairments are not a } \\
\text { result of hearing loss. }\end{array}$ & $\begin{array}{l}\text { Language } \\
\text { impairments } \\
\text { affect: } \\
\text { - short-term } \\
\text { memory } \\
\text { - auditory } \\
\text { memory } \\
\text { - visuo-spatial } \\
\text { - memory } \\
\text { procedural } \\
\text { memory }\end{array}$ & $\begin{array}{l}\text { Language } \\
\text { impairments } \\
\text { affect: } \\
\text { - attention span } \\
\quad \text { (is shortened) } \\
\text { - distractibility }\end{array}$ & $\begin{array}{l}\text { Language } \\
\text { impairments affect: } \\
\text { - speech } \\
\text { perception } \\
\text { - understanding } \\
\text { figural language } \\
\text { - recognition of } \\
\text { letters and words }\end{array}$ \\
\hline $\begin{array}{l}\text { Aging, } \\
\text { Dementia, } \\
\text { Alzheimer's }\end{array}$ & $\begin{array}{l}\text { Dementia and Alzheimer's } \\
\text { are defined as severe loss } \\
\text { of cognitive ability that } \\
\text { disrupts quality of life and } \\
\text { daily activities. While } \\
\text { associated with older } \\
\text { adults, it is not a normal } \\
\text { part of aging. Age-related } \\
\text { decline often shows milder } \\
\text { cognitive impairment. }\end{array}$ & $\begin{array}{l}\text { Aging, Dementia, } \\
\text { Alzheimer's } \\
\text { affects: } \\
\text { - creation of new } \\
\text { memories } \\
\text { - short-term } \\
\text { memory } \\
\text { - memory of } \\
\text { layout, } \\
\text { schedules or } \\
\text { sequences } \\
\text { - prospective } \\
\text { memory } \\
\text { (planning) }\end{array}$ & $\begin{array}{l}\text { Aging, Dementia, } \\
\text { Alzheimer's } \\
\text { affects: } \\
\text { - attention span } \\
\text { and } \\
\text { distractibility } \\
\text { (dementia) }\end{array}$ & $\begin{array}{l}\text { Aging, Dementia, } \\
\text { Alzheimer's affects: } \\
\text { - speech } \\
\text { perception } \\
\text { (dementia and, to } \\
\text { a lesser degree, } \\
\text { age-related } \\
\text { decline) } \\
\text { - spatial/temporal } \\
\text { understanding } \\
\text { may be affected }\end{array}$ \\
\hline $\begin{array}{l}\text { Attention } \\
\text { Deficit/ } \\
\text { Hyperactivity } \\
\text { Disorder } \\
\text { (ADHD) }\end{array}$ & $\begin{array}{l}\text { Attention deficit/ } \\
\text { hyperactivity disorder is } \\
\text { characterized by an } \\
\text { ongoing pattern of } \\
\text { inattention and/or } \\
\text { hyperactivity-impulsivity } \\
\text { that disrupts daily life. }\end{array}$ & $\begin{array}{l}\text { ADHD affects: } \\
- \text { working } \\
\text { memory }\end{array}$ & $\begin{array}{l}\text { ADHD affects: } \\
\text { - attention span } \\
\text { - distractibility } \\
\text { - visual attention } \\
\text { - } \text { selective } \\
\text { attention }\end{array}$ & $\begin{array}{l}\text { ADHD affects: } \\
\text { - } \text { visual processing } \\
\text { speeds }\end{array}$ \\
\hline
\end{tabular}

\subsection{Memory impairments}

All of the identified user groups in section 4.1 tend to exhibit memory impairment, which is defined as the inability to recall what has been learned over time (American Psychiatric Association, 2015). Several of the selected studies pointed to declining memory function as the culprit for identifiable user behaviours and barriers to accessibility on the web. Short-term and working memory impairment impacts how users navigate through web content and page layout. For example, page-to-page navigation of a website with multiple 


\section{ACCESS DENIED}

pages requires working memory as it keeps users situated at all times, helping them navigate to and from necessary pages. Participants with dementia had difficulty grouping concepts and pages together and their impaired working and short-term memory made it difficult to logically organize information and remember their place on a website (Savitch \& Zaphiris, 2006). Unclear web structure or lack of navigation cues presents a barrier to accessibility for those with memory impairments (Lim et al., 2013; Maki et al., 2009).

Impaired visual memory can hamper the learning of symbolic representations of language through icons or pictures (Alm et al., 2005; Armstrong et al., 2010). The multimodal layouts of contemporary websites often use new icons and symbols as representations of common navigational features, such as variations of a standard arrow for "next page" or a plus sign for "more information." Older users in particular may have trouble learning new systems of communication (Ilyas, 2012). Together with an impaired working memory, users with declining memory function may have trouble memorizing and learning the correct mental models for completing routine computer tasks (e.g. completing all the steps to pay a bill online) (Ilyas, 2012; Alm et al., 2005).

Table 4 presents a list of the most common HCI behaviours of users with memory impairments found in the data collected from the structured literature review, which helps directly answer RQ 1.

Table 4 - Impaired Memory Function and Corresponding User Behaviours

\begin{tabular}{|l|l|}
\hline Affected Functions & Common User Behaviours \\
\hline - short-term memory & - have difficulty remembering steps to complete a task \\
- working memory & - overwhelmed by complex interfaces with too many functions or menu \\
- visual memory & items \\
- long-term memory & - have trouble figuring out and remembering new visual or interface \\
- visuo-spatial & metaphors \\
memorv & - have difficultv naviaatina menu svstems and findina the riaht nath
\end{tabular}




\begin{tabular}{|l|l|}
\hline Affected Functions & Common User Behaviours \\
\hline - semantic memory & - lose track of where they are on the page \\
- auditory memory & - may repeat processes already completed \\
- procedural memory & $\begin{array}{l}\text { - have difficulty remembering multiple error notifications when filling out } \\
\text { online forms } \\
\text { - are more prone to confusion or irritability when they cannot figure out } \\
\text { or remember what to do }\end{array}$ \\
&
\end{tabular}

These behaviours shed light on potential barriers to accessibility in the website interface or navigational organization. Websites without clear navigational structure and too much content on a page can confuse users with memory impairments (W3C, 2015). Web page unpredictability (e.g. different visual layouts on every page) reduces cohesion and diminishes the ability of users to learn patterns and adapt, while web-related tasks without clear instructions are setting users up for failure (Ilyas, 2012). These are a few examples of prevalent barriers to web accessibility for users with memory impairments that will be considered in the critical analysis of WCAG 2.0.

\subsection{Attention impairments}

All of the user groups identified in section 4.1 have difficulty with attention to some degree, but users with ADHD have the most severe attention impairments. Impaired attention is defined as difficulty focusing on the task at hand, so individuals are often easily distracted and more impulsive (American Psychiatric Association, 2015). Users with ADHD struggle with attention to detail and the inability to focus attention. This makes decision-making online a daunting task due to the increasing complexity of non-linear navigational structure on the web (Brown, 2009). Users with impaired attention struggle to follow instructions to completion, making finishing online tasks with multiple steps difficult (W3C, 2015). They are also more easily distracted, and given the multimodal web 


\section{ACCESS DENIED}

environment presents an overload of stimuli, pop-up ads and flashy features make

navigation and focusing attention difficult. While most users would claim flashing content a mild distraction, it can be debilitating for those with severe attention impairment (Brown, 2009; Ali-Wabil et al., 2007; W3C, 2015).

Table 5 presents a list of the most common HCI behaviours of individuals with attention impairments as reported in the data collected.

Table 5 - Impaired Attention Function and Corresponding User Behaviours

\begin{tabular}{|l|l|}
\hline Affected Functions & Common User Behaviours \\
\hline - selective attention & - easily distracted by scrolling text, blinking icons, pop-up ads \\
- distractibility & - have trouble following complex or unclear instructions for online \\
- attention span & tasks \\
- visual attention & - have difficulty navigating through irrelevant content to find what is \\
& - needed \\
& - can struggle to focus on web tasks with a lack of rapid response \\
& - have difficulty with sequencing information, such as online forms \\
& - have trouble comprehending long passages of unbroken text or little \\
& - fhite space \\
& of focusing on content
\end{tabular}

These common user behaviours help identify potential barriers to accessibility for users with attention impairments. Websites with long passages of unbroken text, no white space and a lack of obvious visual grouping make it difficult to retain a user's focus.

Scrolling banners, blinking text, sudden changes to the site and background audio are unnecessary distractions that make it nearly impossible for users with attention impairments to navigate (Brown, 2009; Brennan et al., 2005; Rose et al., 2011). Interruptions, such as unasked media events like pop-up ads or automatic video launching, can stall or completely disrupt web tasks. 


\section{ACCESS DENIED}

\subsection{Language impairments}

Language impairment is a broad umbrella term, involving an individual's difficulty understanding text and language, both spoken and written (WebAIM, 2013). All of the user groups mentioned in section 4.1 have some variation of a language impairment. Web accessibility researchers often focus on written text, which is a dominant mode in online communication, but disruptions to speech perception can also occasionally affect web use. Studies on patients with aphasia show most users have difficulty understanding long, complex text and most of these users benefit from additional visuographic contextual support, including appropriately labeled graphics and images (Rose et al., 2011; Dietz et al., 2009). Users with language impairments also struggle to follow text without clear organizational markers, like headers and paragraph structures. Table 6 lists the most common HCI behaviours for users with language impairments as reported in the data collected from the structured literature review.

Table 6 - Impaired Language Function and Corresponding User Behaviours

\begin{tabular}{|l|l|}
\hline Affected Functions & Common User Behaviours \\
\hline - speech perception & - have difficulty understanding complex language \\
- reading comprehension & - cannot perceive/comprehend passages of text \\
- spelling/grammar & - difficulty comprehending spoken text \\
- spatial/temporal & - take a long time to read through a site \\
- perception of text & - struggle with timed content media \\
- visual perception of text & - more easily confused with ambiguous or confusing content \\
& - have trouble interpreting jargon \\
& - have trouble interpreting figurative language \\
& - have trouble interpreting sarcasm \\
& - struggle with word-finding problems
\end{tabular}

The common user behaviours of individuals with language impairments help identify some potential barriers to accessibility. Any complex, ambiguous or confusing language will present a problem for anyone with difficulty processing language; this barrier 


\section{ACCESS DENIED}

proves a particular challenge for web authors to overcome, as will be discussed in section 5.3. Time-based content, such as scrolling headers and purchase buttons that time out, can overwhelm users with language impairments because it takes longer for them to read, comprehend and respond to text. The increasingly common CAPTCHA buttons, which ask users to manually enter jumbled or dictated text to verify against spam bots, can be trouble for those with reading and speech comprehension impairments.

Understanding these user behaviours and potential barriers to accessibility provides context for the following analysis of WCAG 2.0.

\subsection{Content analysis of WCAG 2.0}

As stated in the introduction, the WCAG 2.0 document is a guideline "to make Web content more accessible to people with disabilities" (W3C, 2008). The authors offer an important disclaimer: although the guidelines cover "a wide range of issues, they are not able to address the needs of people with all types, degrees, and combinations of disability" (W3C, 2008). Despite this cautionary claim, these guidelines are readily used for accessibility evaluation in many organizations internationally. The content analysis aims to answer the following: what barriers to accessibility does WCAG 2.0 attempt to flag and measure and how does it address users with cognitive impairments?

\subsection{Web content addressed by WCAG 2.0}

The primary content in the WCAG 2.0 Guidelines introduces 61 success criteria categorized by four major domains: (1) perceivable, (2) operable, (3) understandable and (4) robust. Perceivable criteria are used to evaluate content observable by users with clarity and precision. Operable criteria are used to ensure all interface and navigational 


\section{ACCESS DENIED}

components are usable. Understandable criteria are used to ensure information and the organization of the interface is understood by all. Robust criteria are used to ensure all content can be interpreted by a variety of assistive technologies. Throughout all four domains, the 61 success criteria each concern a particular barrier to accessibility, and since WCAG 2.0 is a guideline for developers, the barriers concern web content exclusively and do not consider or instruct user behaviours. The primary content, which lists the criteria and their objectives, was collected and analyzed. Table 7 lists 34 specific barriers addressed throughout WCAG 2.0 that pertain to web content.

Table 7 - Web Content Barriers Addressed in WCAG 2.0 Main Content

\begin{tabular}{|c|c|}
\hline Major Domain & Web Content Barrier Addressed \\
\hline Perceivable & $\begin{array}{l}\text { - Text alternatives } \\
\text { - Time-based media } \\
\text { - Audio- and video-only content } \\
\text { - Captions } \\
\text { - Audio descriptions or media alternatives } \\
\text { - Sign language } \\
\text { - Information structure } \\
\text { - Meaningful sequence } \\
\text { - Sensory characteristics (shape, size, visual orientation, etc.) } \\
\text { - Colour } \\
\text { - Audio control/background audio } \\
\text { - Contrast } \\
\text { - Visual presentation } \\
\text { - Images of text }\end{array}$ \\
\hline Operable & $\begin{array}{l}\text { - Keyboard traps } \\
\text { - Adjustments to timed content (pausing, stopping, hiding, etc.) } \\
\text { - Interruptions } \\
\text { - Re-authenticating } \\
\text { - Flashing content } \\
\text { - Bypass blocks } \\
\text { - Page titles/headings/labels } \\
\text { - Focus order } \\
\text { - Navigation location }\end{array}$ \\
\hline
\end{tabular}


ACCESS DENIED

\begin{tabular}{|l|l|}
\hline Major Domain & Web Content Barrier Addressed \\
\hline Understandable & - Language of page and sections \\
& - Lexicon (unusual words, abbreviations, jargon) \\
& - Reading level \\
& - Pronunciation \\
& - Changing input \\
& - Navigation consistency \\
& - Identification consistency \\
& - Error identification/suggestion/prevention \\
\hline Robust & - Labels for content that requires user input \\
& - Parsing (all HTML markup is complete and simplified) \\
\hline & - Names/Roles/Values (all HTML is intuitively labeled) \\
\hline
\end{tabular}

Many of the web content barriers apply to multiple user groups, including those with cognitive impairments. Barriers like flashing content, text-alternatives, time-based media and information structure/sequencing apply to users with sensory and cognitive impairments and were frequently mentioned in the results of the usability studies in the structured literature review. When the web content barriers listed in Table 7 are organized by priority level, the majority of the barriers that pertain to users with cognitive impairments are mentioned in level AAA success criteria. Adjustments to background audio, interruptions, flashing content and section headings are barriers only addressed in level AAA criteria and primarily concern users with cognitive impairments. Languagespecific criteria, which include issues with unusual words (e.g. figurative language, idioms, jargon, etc.), abbreviations, reading level and pronunciation, affect users with language impairments and are also found at the level AAA priority. As briefly mentioned in the introduction, level AAA priority criteria are least essential. Completion of these criteria would ensure robust web accessibility, but their practicality and complicated nature prove difficult for implementation, as will be discussed. Level A, on the other hand, is top priority. Some issues in the level A criteria affect those with cognitive impairments, like 


\section{ACCESS DENIED}

error identification and adjustable timing, but they also impact users with sensory and motor impairments.

The overview of web content barriers provides preliminary insight into how WCAG 2.0 divides and prioritizes barriers for particular user groups. The barriers faced by those with cognitive impairments are included but valued at lower priority.

\subsection{Language in WCAG 2.0}

The trend of low prioritization for users with cognitive impairments is reflected in the language of the document. All of the content, including the "Understanding" and "How to Meet" sections, was run through Voyant automated analysis tool to assess the occurrence of unique words. The top 500 most frequently occurring words (excluding stop words) of the 4,590 unique words in the entire document were coded for explicit reference to sensory, motor or cognitive function and the results are shown in Table 8 . Of the 500 most frequently used words, 25 of them made explicit reference to sensory function, such as words like "vision" or "deaf". By contrast, 6 words in the top 500 made explicit reference to cognitive function, such as words like "attention" or "learning". When counted for the number of individual occurrences, words making explicit reference to sensory function were four times more likely to appear in the document than words making explicit reference to cognitive function.

Table 8 - Occurrences of Most Frequent Words in WCAG 2.0 Guidelines

\begin{tabular}{|l|r|r|r|}
\hline & Sensory & Motor & \multicolumn{2}{c|}{ Cognitive } \\
\hline $\begin{array}{l}\text { Number of words in } \\
\text { the top 500 }\end{array}$ & 25 & 1 & 6 \\
\hline $\begin{array}{l}\text { Number of } \\
\text { instances: }\end{array}$ & 1886 & 159 & 480 \\
\hline
\end{tabular}




\section{ACCESS DENIED}

At the most rudimentary level, the word choices of the WCAG 2.0 Guidelines demonstrate a clear and significant preference toward sensory function. During the analysis, there was little ambiguity about interpretation because content was coded for explicit reference to either sensory, motor or cognitive function. There are limitations to this type of technical assessment. It is very possible that content describing an obstacle or accessible solution relevant to a user with cognitive impairments does not make explicit reference to cognitive function whatsoever. It also does not consider the context of the words used nor does it consider multi-word phrases.

To account for these limitations, a manual content analysis was subsequently conducted. To keep the content analysis manageable and within scope, the "Intent" section, which details the goal of the criterion and what user groups benefit from implementation, was assessed. Individual and multi-word phrases were considered, as was the context in which they appear. In order to ensure mutual exclusivity, this coding scheme considered content that could apply to more than one function (e.g. sensory and cognitive function). Content that did not address a particular barrier or function was grouped in an "other" category and, for the purposes of this content analysis, was not considered in any significant detail.

Much like the evaluation of WCAG 2.0's most frequently used words, the content in the "Intent" sections made significantly more mention of sensory impairments than cognitive impairments. Of the words and phrases coded as relevant to accessibility function and barriers, $47 \%$ of the content explicitly addressed sensory disabilities and function while 


\section{ACCESS DENIED}

just under $28 \%$ of the relevant content made explicit mention of cognitive disabilities. The results are featured in Table 9.

Table 9 - Occurrences of Key Words in "Intent" Sections

\begin{tabular}{|c|c|c|c|c|c|c|c|c|}
\hline \multirow[b]{2}{*}{ Instances: } & \multicolumn{2}{|c|}{ Sensory } & \multicolumn{2}{|c|}{ Motor } & \multicolumn{2}{|c|}{ Cognitive } & \multicolumn{2}{|c|}{ Multiple } \\
\hline & $\#$ & $\%$ & $\#$ & $\%$ & $\#$ & $\%$ & $\#$ & $\%$ \\
\hline Level A & 71 & 49.0 & 9 & 6.2 & 27 & 18.6 & 38 & 26.2 \\
\hline Level AA & 29 & 49.2 & 3 & 5.1 & 18 & 30.5 & 9 & 15.3 \\
\hline Level AAA & 48 & 43.2 & 7 & 6.3 & 42 & 37.8 & 14 & 12.6 \\
\hline Whole Document & 148 & 47.0 & 19 & 6.0 & 87 & 27.6 & 61 & 19.4 \\
\hline
\end{tabular}

When broken down by priority level, the occurrences of key words in the "Intent" sections reveal a continued preference toward sensory function over cognitive function. In level A success criteria, content about sensory function makes up $49 \%$ of relevant content while content about cognitive function makes up under $19 \%$ of the content; disproportionately less than the total occurrences in the document as a whole. In the level AA success criteria, the occurrences of content about cognitive function increases to $30 \%$ and jumps up even higher to almost $38 \%$ for level AAA success criteria. The less essential the success criteria (level AAA), the more they have to do with cognitive function. The opposite holds true, as well: the more essential the success criteria, the more likely they concern sensory function. It is also worth noting that regardless of priority level, discussion of sensory function always remains the most common throughout all success criteria.

These results are open to several interpretations. The mention of cognitive function is a likely indication that the success criteria address barriers that impede on users with cognitive impairments. The same can be said for sensory functions. Phrases and content that addressed multiple functions apply to barriers for all users. Consequently, it is inferred 


\section{ACCESS DENIED}

that providing accessible solutions to users with cognitive impairments requires the most knowledge and training for content developers, as they are most likely to be addressed in level AAA success criteria. This idea is consistent with current literature on web development; WebAIM and the W3C acknowledge the inherent difficulty in understanding cognitive disorders compared to sensory disorders (WebAIM, 2013; W3C, 2015). This portion of the content analysis provides a partial answer to RQ 2 and 3, as the data contributes an accurate sample of what user groups, functions and barriers are being addressed by all 61 success criteria in WCAG 2.0 (RQ 2). Knowing how each criterion references cognitive function, and at what priority it is valued, helps answer how WCAG 2.0 addresses the barriers faced by users with cognitive impairments (RQ 3).

\subsection{Detailed analysis of success criteria}

In a 2006 ethnographic study on web usability and assistive technology, users with cognitive impairments expressed a common desire for web developers to "keep it small and simple" when designing websites (Dawe, p. 1145). As the output capabilities of the web stretch across new modalities with advancing technology, small and simple is harder to maintain. Several criteria in the WCAG 2.0 Guidelines aim for simpler functionality and comprehensibility, but in their attempt to achieve simplicity, some of these criteria (and their prioritization) neglect and obstruct the needs of users with cognitive impairments. This part of the analysis explores and compares some of the criteria that reference and address cognitive impairment the most and, subsequently, the least compared to sensory impairments within the Perceivable, Understandable and Operable domain. Since the 


\section{ACCESS DENIED}

Robust domain only addresses two success criteria of the 61 , it was not analyzed in any significant detail.

5.3.1 Criteria in the Perceivable domain. Under the "perceivable" domain, level A success criterion 1.4.1 restricts the use of colour as the "only visual means of conveying information, indicating an action, prompting a response, or distinguishing a visual element" (W3C, 2008). The intent of this criterion is to eliminate the use of colour to convey meaning. For example, a red button that stops an action draws on the cultural convention of a stop sign to produce its meaning. This criterion ensures coloured web content is accessible to those who cannot perceive colour (i.e., users who are colourblind). The content analysis revealed criterion 1.4.1 made eight unique and explicit references to sensory function and two generic reference to multiple users; this is an unsurprising result given colourblindness is a sensory function. The sentiment behind the criterion is welcome, as the use of a singular characteristic, like colour, to convey meaning limits its possible interpretation. There are many other characteristics that, when used to convey meaning or indicate an action, will create a barrier to accessibility for users with cognitive impairments. Modifiable characteristics, like size, shape, foreground/background colours and linespacing, can be adjusted to help users with cognitive impairments. While these characteristics appear in success criterion 1.4.8 (W3C, 2008), the designation of a level AAA priority indicates lesser importance and consideration. The content analysis revealed criterion 1.4.8 had 11 unique mentions of cognitive function, the most of any success criterion. The contrast between the specificity of criterion 1.4.1 and the broadness of 1.4.8, in conjunction with their designated priority levels, suggests that creating perceivable 


\section{ACCESS DENIED}

content for users with cognitive impairments is not reasonable or easily achievable compared to users who are colourblind.

5.3.2 Criteria in the Understandable domain. Similar findings are present throughout the WCAG 2.0 Guidelines. The "understandable" domain attempts to ensure that content and site navigation are understood by all users, especially success criteria 3.1.3, 3.1.4 and 3.1.6, which advise developers on appropriate use of various linguistic features. Criterion 3.1.3 requires content authors provide a mechanism "for identifying simple definitions of words or phrases used in an unusual or restricted way, including idioms and jargon” (W3C, 2008). As articles in the structured literature review state: users with impairments to language comprehension function may struggle recognizing figurative language (Rose et al., 2011; Brandenburg et al., 2013; W3C, 2015). Criterion 3.1.4 calls for a similar mechanism for abbreviations, which would identify "the expanded form or meaning of the abbreviation" (W3C, 2008). Abbreviations often require prior knowledge and a sense of context to be understood, posing an obstacle for users with intellectual, reading or memory impairments. Criterion 3.1 .6 concerns pronunciation, suggesting a mechanism that could identify "specific pronunciation of words where meaning of the words, in context, is ambiguous without knowing the pronunciation" (W3C, 2008). This type of mechanism would benefit anyone with a reading and learning impairment or anyone with reduced language comprehension function (Dietz et al., 2009; W3C, 2015).

The content analysis shows criteria 3.1.3, 3.1.4 and 3.1.6 mention some aspect of cognitive function at least $50 \%$ more often than sensory function, reinforcing their relevance to users with cognitive impairments. Like criterion 1.4.8, all three criteria are 


\section{ACCESS DENIED}

level AAA priority and are potentially powerful solutions that would benefit those with learning and cognitive impairments, but are unlikely to be implemented. Mechanisms, like the abbreviation or pronunciation mechanisms described, are complicated and currently not readily available in the public domain, requiring expert knowledge and programming ability. The average web content developer will not be able to implement the suggestions. The WCAG 2.0 authors have the right idea behind the criteria but suggest a highly impractical solution to remedy the barrier.

Criterion 3.1.5 also concerns language and is arguably the most contentious of the entire guideline. Aside from being another level AAA priority criterion, it is both ambitious and seemingly unfeasible by its very nature. Criterion 3.1.5 suggests text content that has a reading level "more advanced than the lower secondary education level" should have a supplemental version "that does not require reading ability more advanced than the lower secondary education level" (W3C, 2008). This means content developers must either create auxiliary written content when developing a website or write simply from the start. The first alternative is time consuming and potentially expensive, while the other alternative sounds easy, but is difficult to execute. Many developers and content authors believe they are writing more clearly and concisely than they actually are. Take, for instance, the very authors of the WCAG 2.0 Guidelines. When the section on reading level was run through an automated test that scored readability based on five different common formulas ${ }^{1}$, the passage was determined to be written at the grade 12 level. By their very own recommendations, this reading level is too advanced for many user groups with cognitive impairments, such as those with language difficulties, aphasia, dyslexia and dementia 


\section{ACCESS DENIED}

(Brennan et al., 2005; Hellman, 2012; Karlson et al., 2011; W3C, 2015). In fact, the content is likely too advanced for the general public.

This informal readability test brings up another critical issue for criterion 3.1.5: it is as difficult to evaluate as it is to execute. Machine testability is based on rigid formulae, typically assessing readability based on words, word length, sentences and syllables. These are useful indicators of readability, but are prone to false negatives. Several other factors that are not incorporated into an algorithm can determine reading level: the length of the passage, how the passage is broken up contextually, idea segmentation (e.g. having one idea per paragraph) and audience profile. At the same time, the criterion is not truly reliably human testable. Having knowledgeable testers determine whether content is written "as clearly and simply as possible" (W3C, 2008) without the use of algorithms requires a subjective assessment, and having eight out of ten testers agree on a content's readability is unlikely (Brajnik et al., 2012). The evaluative uncertainty of criterion 3.1.5 speaks to the larger issue of testability that plagues WCAG 2.0 (see: section 6.0).

Other criteria under the "understandable" domain can been interpreted as detrimental to users with cognitive impairments. Criterion 3.3.1 concerns error identification, such as the notifications received when filling out a form or entering a password incorrectly. The criterion states "if an input error is automatically detected, the item that is in the error is identified and the error is described to the user in text" (W3C, 2008). As a level A priority criterion, it is the most essential and mandatory. By having the error identification as a text-only requirement, as opposed to modifiable and contextsensitive content suggested in level AAA criterion 3.3.5 (W3C, 2008), there is an automatic 


\section{ACCESS DENIED}

barrier created for users with language comprehension impairment or difficulty reading, including those with dyslexia and general language impairments (Al-Wabil et al., 2007). For users with assistive technologies that use an auxiliary output other than text, the sudden change in modality can add to the confusion.

5.3.3 Criteria in the Operable domain. As the web landscape continues to evolve, many of the criteria are becoming outdated. Criteria that concern navigation presume a static web structure where, in actuality, much of today's web content is user generated or dynamic. User generated web content is equivalent to having multiple authors working on a site. This poses a challenge to enforcing particular success criteria, like level AA criterion 2.4.6 that concerns headings and labels or level AAA criterion 2.4.9 that concerns identifiable link purposes. A web developer can make sure these criteria are met but user generated content holds no such guarantees. Many popular sites rely on dynamic user generated content, including most social media platforms (e.g. Facebook, Twitter) and discussion forums (e.g. Reddit), where it is impossible to guarantee the WCAG 2.0compliance of all individual user postings. Rather than change the rules for dynamic content from the web developer's end, there needs to be a new approach to the guidelines that fully considers the evolving, multimodal web landscape.

The content analysis demonstrates with strong evidence that WCAG 2.0 addresses the barriers faced by users with cognitive impairments significantly less frequently than sensory impairments. The relegation of several important guidelines to level AAA status indicates less assurance that these barriers can be adequately addressed by the average web content author. More education about the user experiences of individuals with cognitive 


\section{ACCESS DENIED}

impairments is needed; this statement speaks to both the need to study usability and cognitive impairments, as well as the need to further educate web developers about cognitive accessibility.

\subsection{Discussion: Identifiable issues with WCAG 2.0, web accessibility and cognitive impairments}

The content analysis sheds light on larger critical issues about web accessibility. Creating a thoughtful, evidence-based dialogue about the following issues is the first step to ensuring web equality for users with cognitive impairments.

\subsection{Defining what is accessible}

In 2005, a pilot study investigated users with developmental cognitive impairments (DCDs) and recorded their experience navigating two websites certified as accessible by the W3C (Small et al.). As users navigated the websites, researchers tracked four determinants of navigational performance: (1) spatial awareness, (2) situational awareness, (3) task-set switching (i.e. being able to move from one task to another) and (4) anticipated system response (i.e. knowing how an operating system will respond to a command). Across all four markers, users with DCDs struggled significantly, with a majority of the participants having difficulty navigating from page to page (Small et al., 2005). Despite W3C certification, it was evident that these websites were not accessible.

The pilot study was small in scope, assessing only two websites, but it spoke to a bigger question: what does it mean for a website to be accessible? By the W3C's standards, accessibility is determined by meeting the minimum requirements of the 61 testable

criteria. Current WCAG 2.0 Guidelines require all success criteria be testable by algorithm 


\section{ACCESS DENIED}

or a knowledgeable human tester, but testability within both domains has its shortcomings. Machine testability eliminates any subjective assessment, which saves a lot of time testing technical criteria such as colour contrast ratios, but proves unreliable for more subjective criteria such as reading level, as discussed previously. Human testability can test content that algorithms cannot, but achieving $80 \%$ agreeability among testers is not likely. The very subjective nature of several criteria makes testability difficult. For example, success criteria 1.1.1 requires alt-text labels for all non-text components, such as images. The intent of the criteria is "to make information conveyed by non-text content accessible through the use of a text alternative" (W3C, 2008). Alt-text labels are determined by the content creators and developers, not machines. Developers assign an appropriate label to an image based on their subjective understanding of the image's meaning. Some images are more straightforward than others and, since no machine exists to automatically interpret image meaning, it must be tested by human experts. Finding agreeability is difficult because everyone, including users with disabilities, interprets pictures differently. It is difficult to assert that the same information is conveyed to all users through text alternatives consistently.

Several studies that explore human testability confirm this assumption. As discussed in the literature review, the study by Brajnik et al. demonstrated that finding $80 \%$ agreeability "almost never happened" in real-world audits (2012). Alonso et al. explored the topic in further depth in their 2010 study, where they found that when knowledgeable human testers were asked to evaluate the same website, only $65 \%$ of the level A success criteria could achieve $80 \%$ agreeability (Alonso et al., 2010). The more complex the 


\section{ACCESS DENIED}

criteria, the more experts disagreed; of the level AA and AAA success criteria, 47\% were deemed reliably human testable. This is problematic for users with cognitive impairments as these criteria tend to concern cognitive function more than level A criteria. These studies begin to validate a common concern of WCAG 2.0: testability is not really possible.

Thus, it cannot be said with any certainty or confidence that meeting the criteria set forth by the W3C affirms a website is accessible. The guidelines offer well-intentioned recommendations but sacrifice important accommodations in the name of testability. The prescriptive nature of the guidelines ignore the diversity of the user's experience. As the research and literature demonstrates, the experiences of users with cognitive impairments are varied and unique. Measurement based solely on the testable guidelines overlooks broader, real-world context and fails to deliver a truly accessible experience.

\subsection{The problem with level AAA priority}

In the pursuit of answering how WCAG 2.0 addresses barriers for users with cognitive impairments, many of the conclusions in this MRP rest on the assumption that level AAA designation is problematic. While the $\mathrm{W} 3 \mathrm{C}$ indicates these particular criteria are the least essential (W3C, 2008), that does not mean they are not useful. The measure of how essential criteria may be factors in the potential labour of the web developer and content author. Level AAA criteria often involve laborious tasks and complex mechanisms; it would be impractical to make these tasks mandatory. Level A criteria provide feasible solutions to some (but certainly not all) issues of accessibility, especially for barriers to sensory impairments. The accommodations recommended by the level A criteria are simple, do not require extensive accessibility knowledge and are automated by most content 


\section{ACCESS DENIED}

management systems. Many organizations are pleased with satisfying level A criteria and nothing more.

This is why level AAA priority is a problem for users with cognitive impairments.

While WCAG 2.0 recommends several useful fixes at the level AAA priority, implementation is deemed least essential and is almost always bypassed. For example, the AODA law in Ontario actively uses WCAG 2.0 criteria as a baseline measure. By January 1, 2014, all public and private sector business websites must have level A compliance. By January 1, 2021, level AA compliance will be required and failure to comply can result in a $\$ 50,000$ fine (AODA, 2014). There are no plans to have level AAA compliance be mandatory. Rather than become instructional guidelines, the level AAA criteria remain an elusive characteristic of ideal, but unachievable, accessibility. Subsequently, web developers become complacent with only meeting the minimum requirements. When there are no legal or financial implications for inaccessibility, it becomes much more tempting and practical to take the easier route. This is problematic for users with cognitive impairments, who benefit most from level AAA requirements compared to level A and AA. Complacency with meeting the minimum requirement sets a dangerous precedent.

Deploying "good enough" accessibility techniques will fail to consider "a wider measure of user experience in accessible measurement" (Sloan \& Kelly, 2011, p. 1). Ultimately, when it comes to the web equality of users with cognitive impairments, "good enough" is not good enough. 


\section{ACCESS DENIED}

\subsection{Conclusion}

The content analysis of the WCAG 2.0 Guidelines reveals the document's failure to consider and, more importantly, value the complexity of cognitive impairments. The W3C authors demonstrate through their use of language a clear and significant bias toward users with sensory impairments by prioritizing their needs above users with cognitive impairments. Sensory impairments are more frequently associated with level A priority success criteria, as the occurrences of key words and the evaluation of accessibility barriers demonstrate. Cognitive impairments, however, receive less attention than sensory impairments in critical areas and in the document as a whole, and are deemed less essential by the W3C's own priority categorization.

WCAG 2.0's insufficient consideration of cognitive impairments and their inherent intricacy is consistent with the little research that exists on the subject. Studies have exposed the fallible testability of WCAG 2.0 success criteria with comprehensive usability testing, where users with cognitive impairments report difficulty navigating and communicating online (Small et al., 2005; Brajnik et al., 2012). Even though websites meet the minimum WCAG 2.0 requirements, they are still inaccessible to users with cognitive impairments. When web content developers and organizations rely solely on WCAG 2.0 success criteria to guide accessibility, they are more likely to neglect the needs of users with cognitive impairments. Given the cognitive decline that comes with age, many of these neglected users will be seniors. In North America, the senior population (age 65 and up) is experiencing the largest annualized growth rate (9\%) of any age group, almost nine times higher than the population aged 35-44 (Neilsen, 2013). The percentage of seniors on the 


\section{ACCESS DENIED}

Internet is growing as well, with a growth rate of $16 \%$ per year (Neilsen, 2013). With an aging population that browses, communicates and shops online, many businesses and organizations will need accessible solutions to accommodate users with cognitive impairments sooner rather than later.

\subsection{Recommendations}

The testable success criteria of the current WCAG 2.0 Guidelines do not sufficiently or comprehensively address cognitive impairments, which sends the message that cognitive impairments are not worth accommodating. Until the guidelines receive a much-needed updated, content developers and authors must think beyond testable success criteria and approach cognitive web accessibility more holistically. Understanding how users with cognitive impairments communicate and behave online will better serve those individuals.

The following brief, high-level recommendations for web developers are a cumulative result of the structured literature review and content analysis, identifying general techniques for developers that are not explicitly mentioned in the WCAG 2.0 success criteria.

7.1.1 Create manageable content. Guideline 3.1 in WCAG 2.0 ensures the readability of text content by recommending an assessment of reading level by automated testing. These measurements alone do not provide a complete assessment of content's readability, as the content analysis demonstrated, and web developers should be encouraged to view criteria more holistically to determine if the content is understandable. Web authors should approach creating discursive and non-discursive content in manageable "chunks" that do not overload the attention or memory of users. Individual web pages should have 


\section{ACCESS DENIED}

one subject each, while content authors should limit each paragraph and sentence to the presentation of a single idea. The same rules apply to non-discursive content: images, videos and multimedia should not crowd one particular area. Creating manageable content divides the cognitive load into reasonable tasks that users with impaired attention, memory or language can cope with.

7.1.2 Use distinct visual affordances. Level A criteria that fall under the "perceivable" domain require text alternatives for all non-text content. While this technique should always be practiced as it benefits most user groups, it should not discourage web developers and content authors from using images and visual media to convey meaning. Actionable items, or any web item with which users can interact, should have an obvious visual style that indicates what it does. For example, a button on a website should physically resemble a button that would be pushed. Designers need to approach using "flat UI" with caution, as this a recent design trend of incorporating minimalist, two-dimensional illustrations can be difficult for users with cognitive and visual perception impairments. Visual affordances should be distinct and consistent across the entire website. Using images as a way to express meaning, in addition to text-based content, provides an appropriate alternative for those who struggle processing language quickly and efficiently. For these (and all) web users, expediency is everything.

7.1.3 Consider user input. Responsive design is quite common in the current web landscape, as user input is required to fill out forms, complete purchases and sign-in to accounts. While guideline 3.3 concerns input assistance, it primarily instructs developers to acknowledge errors when users make mistakes filling out forms and it does not consider the 


\section{ACCESS DENIED}

design of the form itself. Web designers need to remember that the sequential and often lengthy nature of many online forms present a challenge to users with cognitive impairments. Forms should be designed for simple data entry with appropriately-sized entry fields and, much like any other content, should be divided into manageable chunks. The appearances of forms should remain consistent across the website with clearly labeled text and pictographic directions, as this will help users with severe attention or memory impairments, like those with aphasia.

\subsection{Moving forward}

Cognitive impairments may obstruct accessibility in ways that differ greatly from visual, auditory and motor impairments, but solutions to cognitive accessibility barriers are truly universal. Creating content that is simple, intuitively organized and unambiguous benefits all web users and evens the playing field. While the WCAG Guidelines introduced web accessibility into the public and legal discourse back in 1999, the now outdated criteria prohibit users with cognitive impairments from fully accessing the web. As the way we communicate online continues to evolve, so too must the W3C's approach to dealing with the entire spectrum of disability. Accommodating cognitive impairments requires a fair amount of flexibility, and the sole use of rigid, testable criteria does a disservice to millions of users. With an aging, Internet-using population in Canada and around the globe, it is long overdue for the $\mathrm{W} 3 \mathrm{C}$ and web content developers to broaden the perception of "inclusive design". 
ACCESS DENIED

\section{References}

Al-Wabil, A., Zaphriris, P. \& Wilson, S. (2007). Web navigation for individuals with dyslexia: An exploratory study. Universal Access in Human Computer Interaction, 4554(1), 593-602

Alm, N., Dye, R., Astell, A., Ellis, M., Gowans, G. \& Campbell, J. (2005). Making software accessible to people with severe memory deficits. In Proceedings of Accessible Design in the digital world.

Alm, N., Dye, R., Gowans, G., Campbell, J., Astell, A. \& Ellis, M. (2007). A communication support system for older people with dementia.

Alonso, F., Fuertes, J., Gonzalez, A. \& Martinez, L. (2010). On the testability of WCAG 2.0 for beginners. In Proceedings of the International Cross-Disciplinary Conference on Web Accessibility.

Altinsoy, M. \& Hempel, T. (2011). Multimodal user interfaces: Designing media for the auditory and tactile channels. In Handbook of Human Factors in Web Design $\left(^{\text {nd }}\right.$ ed., pp. 127-152). Boca Rotan: CRC Press.

American Psychiatric Association. (2013). ADHD. Retrieved May 9, 2015, from http:// www.apa.org/topics/adhd/

American Psychiatric Association. (2015). DSM-5. Retrieved May 9, 2015, from http:// www.dsm5.org

Armstrong, N., Nugent, C., Moore, G. \& Finlay, D. (2010). Developing smart phone applications for people with Alzheimer's disease. In Proceedings of the IEEE/EMBS 


\section{ACCESS DENIED}

Region 8 International Conference on Information Technology Applications in Biomedicine.

Astell, A., Alm, N., Gowans, G., Ellis, M., Vaughan, P., Dye, R. \& Campbell, J. (2009). Working with people with dementia to develop technology: The CIRCA and Living in the Moment projects. Journal of Dementia Care, 17(1), 36-39.

Astell, A., Ellis, M., Alm, N., Dye, R., Gowans, G. \& Vaughn, P. (2006). "Living in the Moment": Developing an interactive multimedia activity system for elder people with dementia. In Proceedings of the International Workshop on Cognitive Prostheses and Assisted Communication.

Brajnik, G., Yesilada, Y. \& Harper, S. (2012). Is accessibility conformance an elusive property? A study of validity and reliability of WCAG 2.0. ACM Transactions on Accessible Computing, 4(2), 1-27.

Brandenburg, C., Worrall, L., Rodriguez, A. \& Copland, D. (2013). Mobile computing technology and aphasia: An integrated review of accessibility and potential uses. Aphasiology, 27(4), 444-461.

Brennan, A., Worrall, L. \& McKenna, K. (2005). The relationship between specific features of aphasia-friendly written material and comprehension of written material for people with aphasia: An exploratory study. Aphasiology, 19(8), 693-711.

Brown, V. (2009). Individuals with AHDH lost in hyperspace. Childhood Education, 86(1), $45-48$. 


\section{ACCESS DENIED}

Caldwell, B. \& Vanderheiden, G. (2011). Access to web content by those with disabilities and others operating under constrained conditions. In Handbook of Human Factors in Web Design (2 ${ }^{\text {nd }}$ ed., pp. 371-402). Boca Rotan: CRC Press.

Clarkson, P.J., Coleman, R., Keates, S. \& Lebbon, C. (2003). Inclusive design: Design for the whole population. London: Springer-Verlag.

Cooper, M., Sloan, D., Kelly, B. \& Lewthwaite, S. (2012). A challenge to web accessibility metrics and guidelines: Putting people and processes first. In W4A 2012: $9^{\text {th }}$ International Cross-Disciplinary Conference on Web Accessibility.

Dawe, M. (2006). Desperately seeking simplicity: How young adults with cognitive disabilities and their families adopt assistive technologies. In Proceedings of the SIGCHI Conference on Human Factors in Computing Systems, 1143-1152.

Dietz, A., Hux, K., McKelvey, M., Beukelman, R. \& Weissling, K. (2009). Reading comprehension by people with chronic aphasia: A comparison of three levels of visuographic contextual support. Aphasiology, 23(7-8), 1053-1064.

Dobosz, K. Dobosz, M., Fiolka, T., Wojaczek, M. \& Depta, T. (2014). Tablets in the rehabilitation of memory impairment. Computers Helping People with Special Needs, 399-402.

Giakoumis, D., Kaklanis, N., Votis, K. \& Tzovaras, D. (2014). Enabling user interface developers to experience accessibility limitations through visual, hearing, physical and cognitive impairment simulation. Universal Access in the Information Society, 13(2), 227-248. 


\section{ACCESS DENIED}

Hellman, R. (2012). Usable user interfaces for persons with memory impairments. Advanced Technologies and Societal Change, 167-176.

Ilyas, M. (2012). A study of web accessibility barriers for older adults. Journal of Emerging Trends in Computing and Information Sciences, 3(5), 806-813.

Karlson, E., Axelsson, K., Zingmark, K. \& Savenstedt, S. (2011). The challenge of coming to terms with the use of a new digital assistive device: A case study of two persons with mild dementia. Open Nursing Journal, 5, 102-110

Kress, G. (2010). Multimodality: A social semiotic approach to contemporary communication. London: Routledge.

Kress, G., \& van Leeuwen, T. (2001). Multimodal discourse: The modes and media of contemporary communication. London: Bloomsbury Academic.

Learning Disabilities Association of Ontario. (2011). What are LDs? Retrieved April 15, 2015, from http://www.ldao.ca/introduction-to-ldsadhd/introduction-to-ldsahd/

Lim, F., Wallace, T., Luszcz, M. \& Reynolds, K. (2013). Usability of tablet computers by people with early-stage dementia. Gerontology, 59, 174-182

Mahmud, J. \& Ramakrishnan, I. (2011). Transaction models for web accessibility. World Wide Web, 15(4), 383-408.

Maki, O., \& Topo, P. (2009). User needs and user requirements of people with dementia: Multimedia application for entertainment. In Dementia, Design and Technology: Assistive Technology Research Vol. 24. Amsterdam: IOS Press.

Mariger, H. (2006). Cognitive disabilities and the web: Where accessibility and usability meet? Retrieved March 30, 2015, from http:/ncdae.org/resources/articles/cognitive/ 


\section{ACCESS DENIED}

McCarthy, J. \& Swierenga, S. (2009). What we know about dyslexia and web accessibility: A research review. Universal Access in the Information Society, 9(2), 147-152.

Meiland, F., De Boer, M., Van Hoof, J., Van Der Leeuw, J., De Witte, L., Blom, M. \& Droes, R. (2012). Functional requirements for assistive technology for people with cognitive impairments and dementia. Communications in Computer and Information Sciences, 277, 146-151.

Neilsen, J. (2000). Designing Web Usability: The Practice of Simplicity. Indianapolis: New Riders.

Neilsen, J. (28 May 2013). Seniors as web users. Retrieved 15 June 2015, from www.nngroup.com/articles/usability-for-senior-citizens/

Romen, D. \& Svanaes, D. (2012). Validating WCAG versions 1.0 and 2.0 through usability testing with disabled users. Universal Access in the Information Society, 11(4), $375-385$.

Rose, T. Worrall, L., Hickson, L. \& Hoffmann, T. (2011). Exploring the use of graphics in written health information for people with aphasia. Aphasiology, 25(12), 1579-1599.

Savitch, N. \& Zaphiris, P. (2006). Accessible websites for people with dementia: A preliminary investigation into information architecture. Computers Helping People with Special Needs, 144-151.

Sevilla, J., Herrara, G., Martinex, B. \& Alcandtud, F. (2007). Web accessibility for individuals with cognitive deficits: A comparative study between an existing commercial web and its cognitively accessible equivalent. ACM Transactions on Computer-Human Interaction, 14(3), 1-25. 


\section{ACCESS DENIED}

Sloan, D. \& Kelly, B. (2011). Web accessibility metrics for a post-digital world. In Website Accessibility Metrics Symposium.

Small, J., Schallau, P., Brown, K. \& Appleyard, R. (2005). Web accessibility for people with cognitive disabilities. In Proceedings of the 2005 Conference on Human Factors in Computing Systems, 2-7.

Statistics Canada. (2012). Disability in Canada: Initial findings from the Canadian Survey on Disability. Retrieved 2 June, 2015, from http://www.statcan.gc.ca/pub/89-654-x/ 89-654-x2013002-eng.htm

Van Rijn, H., Johnson, A. \& Taatgen, N. (2011). Cognitive user modeling. In Handbook of Human Factors in Web Design (2 ${ }^{\text {nd }}$ ed., pp. 527-541). Boca Rotan: CRC Press.

Vigo, M., Brown, J. \& Conway, V. (2013). Benchmarking web accessibility evaluation tools: Measuring the harm of sole reliance on automated tools. In W4A 2013: $10^{\text {th }}$ International Cross-Disciplinary Conference on Web Accessibility.

Wachowiak, M., Wachowiak-Smolikova, R. \& Fryia, G.(2010). Practical considerations in human-computer interaction for e-Learning systems for people with cognitive and learning disabilities. International Journal of Informational Studies, 2(1), 60-70.

Waterworth, E. \& Waterworth, J. (2009). Designing ICT for the over 80s. In Dementia, Design and Technology: Assistive Technology Research Vol. 24. Amsterdam: IOS Press.

WebAIM. (2013, August 9). Cognitive introduction. Retrieved February 23, 2015, from http://webaim.org/articles/cognitive. 


\section{ACCESS DENIED}

Wei, L. (2012). Number Matters: The multimodality of Internet use as an indicator of the digital inequalities. Journal of Computer-Mediated Communication, 17(3), 303-318.

W3C. (11 December 2008). Web Content Accessibility Guidelines (WCAG) 2.0. Retrieved March 5, 2015, from http://www.w3.org/TR/WCAG20/

W3C. (15 January 2015). Cognitive accessibility user research: W3C first public working draft. Retrieved April 15, 2015, from http://www.w3.org/TR/coga-user-research 